\title{
“MINHA VOZ ENROUQUECE": \\ A METONÍMIA NA POESIA DE BORIS PASTERNAK
}

Olga Kempinska*

RESUMO: A coincidência da invenção da dicção futurista, da qual participa muito ativamente a poesia de Boris Pasternak, com a confirmação da eficácia prática dos discursos ideológicos e propagandísticos no tempo da revolução e da guerra, causou a ruptura da fronteira entre arte e vida, fazendo com que a linguagem poética passasse a ocupar um lugar incerto, próximo dos discursos da política e da religião. A encenação da vOz que, além de ser marcada pelo sintoma afirma-se em seus aspectos de uma técnica do corpo, convencional e inscrita no âmbito de uma tradição cultural, torna-se o desafio do poema "Poesia", traduzido no Brasil por Haroldo de Campos. Encenando uma voz que ganha sua eficácia no nível inferior da expressão, o texto aponta para uma perturbadora semelhança entre as características da vOZ do poeta da revolução e os desvios da enunciação pública de um discurso político. Henri Meschonnic insiste em sua crítica antropológica do ritmo na dimensão demagógica e na iminência do desnudamento do registro patológico inerentes a uma técnica do corpo por demais singularizada. A eficácia da palavra poética de Pasternak articulada pela metonímia aproximase, de fato, da palavra ideologicamente comprometida praticada no âmbito dos ritos e dos rituais e, nesse sentido, o poema "Poesia" leva à formulação de uma crítica de certas acepções do engajamento da literatura e da arte.

PALVRAS-CHAVE: Linguagem poética; Metonímia; Vanguarda; Violência; Voz.

Dentro do espaço heterogêneo e dinâmico da literatura articulado pela divisão em gêneros, a relação que se tece em diferentes épocas entre a política e a poesia é a mais problemática, uma vez que a dicção especificamente lírica pressupõe antes de mais nada a afirmação da subjetividade. A inevitável inscrição do sujeito no discurso e, com isso, na

\footnotetext{
* Doutora em História Social da Cultura pela Pontifícia Universidade Católica do Rio de Janeiro (Puc-RJ). Professor Adjunto da Universidade Federal Fluminense (UFF).
} 
história realiza-se sobretudo por meio da disposição rítmica da poesia, encontrando na voz seu suporte mais eloquente. Ao mesmo tempo, quando encenado, o ritmo, que não raramente faz com que se confunda a voz do poeta com a voz do poema, coloca em questão a autonomia da linguagem poética, assinalando destarte seu desafiante contato com outros discursos, inclusive com o da história e da política.

É ao poeta Boris Pasternak (1890-1960) que devemos não apenas “a mediação da relação entre Tsvetáieva e Rilke” (GRZYWACZ, 1996, p. 218), nos anos 20, como também a formulação da identidade da poesia enquanto uma "etimologia do sentimento" (DENIS, 2006, p. 76), que constituirá mais tarde uma das acusações mais sérias de sua obra formuladas pelo regime soviético. A descrição da importância da poeta dissidente Marina Tsvetáieva para a elaboração de sua própria dicção poética possui como sua base retórica a metonímia e é justamente essa relação entre a linguagem poética e o uso da metonímia, inscrita não apenas no âmbito das discussões do futurismo russo, como também no ambiente do exílio da amiga poeta causado pela violência revolucionária e pela guerra civil, que constitui o núcleo do presente trabalho:

Tu existias em sonho, mas também em analogia com as paredes, com o soalho, o tecto, num estado de coesão antropomórfica com o ar e a hora: Tsvétaïeva, era a linguagem que se descobria em tudo aquilo a que o poeta se dirige a vida inteira sem esperança de obter resposta. (DENIS, 2006, p. 104)

A grande dificuldade de se encontrar para ela a denominação certeira é uma das características mais importantes e mais provocadoras da poesia de Pasternak, muito lida nos tempos da revolução, muito influente para os poetas acmeístas e muito admirada por Vladimir Maiakovski que sabia vários de seus versos de cor. O próprio Pasternak integrou, aliás, o grupo chamado "Centrifuga”, "o mais efémero” (HEISTEIN, 1975, p. 21) das quatro formações que compuseram o futurismo russo. O grupo distinguiu-se no cenário vanguardista por ter exaltado os princípios construtivos do espaço lírico que tem como os principais mecanismos de sua configuração as imagens formadas pela lógica da contiguidade, levando à articulação da "poesia do 'sdvig' (deslocamento)” (LANNE, 1993, p. 53). 


\section{A poética da metonímia}

Em seu sugestivo ensaio de 1935, Roman Jakobson descreve o gênero lírico enquanto caracterizado pelo uso da primeira pessoa e do tempo verbal presente, insistindo no teor eminentemente metonímico da dicção poética de Pasternak (Cf. AUTOUTURIER, 1995), baseada na associação pela proximidade. Em seus poemas "as imagens do mundo em volta funcionam como reflexos contagiosos ou expressões metonímicas do eu do poeta" (JAKOBSON, 1969, p. 141). Dentre os procedimentos metonímicos mais praticados por Pasternak destacam-se, assim, a antropomorfização, a substituição do todo por uma parte e vice-versa, da causa pelo efeito, das relações espaciais por temporais, os mais característicos sendo "o uso de uma ação em vez de um agente, da condição de um homem ou de uma de suas características ou de um de seus atributos em vez do próprio" (JAKOBSON, 1969, p. 142).

Uma poética dominada pela ordem metonímica coloca em questão a nitidez dos contornos dos objetos, de modo a confundir esses objetos, eventualmente levando a sua decomposição, tal como as figuras na pintura cubista. As imagens poéticas tornam-se, assim, estranhamente contagiosas. Como veremos, no poema "Poesia" a dicção própria confunde-se com a dicção do outro, mostrando, com isso também o quanto são incertos os limites dos grupos artísticos.

Enquanto tal, a metonímia é "um processo de representação no qual uma palavra ou um conceito ou um objeto é utilizada no lugar da outra pela contiguidade ou pela causalidade". (AL-SHARAFI, 2004, p. 1). Assim, a operação associativa da metonímia baseiase ora na proximidade física ora na cognitiva. Ao comentar o exemplo da relação metonímica apresentado por Aristóteles, (Uma taça é para Dionísio aquilo que um escudo é para Ares), que, diferentemente de Jakobson (1995), não a compreende como oposta à metáfora, Abdul Gabbar Mohammed Al-Sharafi descreve-a como uma relação "de invenção para invenção” (2004, p. 13). Além disso, segundo os estudos do Grupo MU, “a metáfora é denotativa, ao passo que a metonímia é conotativa” (AL-SHARAFI, 2004, p. 43). 
Na pintura cubista, o funcionamento da metonímia parece corresponder sobretudo às diversas técnicas da colagem, que acolhem os matériais heterogêneos ao fazer pictórico, ressaltando, ao mesmo tempo sua inquietante continuidade, transposta em termos de uma aderência: “Colam-se no quadro pedaços de papeis, derrama-se areia. Enfim, usa-se cartão, madeira, latão etc." (JAKOBSON, 2018, p. 149). Da maneira análoga, no poema metacriativo intitulado "Poesia", de 1922, e traduzido por Haroldo de Campos, a "poesia" encontra sua expressão metonímica na voz do "eu" lírico e na tematização da presença da página em branco:

Poesia, minha voz enrouquece

De juras sobre ti: estertor

Não pose melíflua de cantor.

Vagão de terceira no verão,

Pareces. Subúrbio e não refrão.

Abafas como Iamskaia: és maio,

Cheverdin, o reduto noturno,

Onde nuvens exalam seus guais

e se vão, cada qual por seu turno.

E em dobro, pela trama dos trilhos, -

Arrabaldes não são estribilhos, -

Se rojam das estações à casa,

Não cantando, formas hebetadas.

Renovas que a chuva põe nos cachos

Até de manhã, num fio contínuo,

Pingam seus acrósticos do alto

Enquanto lançam bolhas de rimas.

Poesia, quando sob a torneira

Um truísmo é um balde de folha

Vazio, mais o jato se despeja.

Eis o branco da página: jorra!

(CAMPOS, 2001, pp. 189-190) $^{1}$ ${ }^{1}$ Поэзия, я буду кцяться / Тобой, и кончу, прохрипев: / Ты не осанка сладкогласца, / Ты - мето с местом
в третьем классе, / Ты - пригород, а не припев. 
"Para mim os poemas sem rimas não existem" (apud. JAKOBSON, 1992, p. 62), afirmava o poeta e, com efeito, a urgência da repetição expressa-se não penas no agenciamento das quadras, como também nas imagens da respiração agoniada, do movimento do trem e da passagem das imagens vistas pela janela do vagão, das gotas e do respingar da água de chuva. A irmã do poeta, ao comentar a estrutura de seus textos, alguns dos quais verteu para o inglês, descreve-os também como estritamente rítmicos para insistir na preponderância da poética da sonoridade:

Temo que continuo sem compreender de que maneira as palavras tais como "I" e "destiny", tão frequentemente usadas pelos poetas ingleses podem ser tratadas como rimas: ou "majority" e "only", e até mesmo "love" e "remove". A semelhança visual das últimas letras nada significa para meu ouvido; e apenas meu ouvido frui a assonância. Não tenho dúvidas de que meu irmão compartilhava dessa opinião. (STALER, 1972, p. 12)

Destarte, o uso da metonímia torna-se propício à evocação dos efeitos da linguagem poética, sobretudo em seus aspectos da quebra da distância estética, que corresponde no poema às sensações olfativas.

\section{A voz e a violência rítmica}

Benedito Nunes descreve o percurso textual de Haroldo de Campos utilizando um dos desdobramentos metonímicos da voz, estranhamente desacreditado no poema de Pasternak, a saber, o canto: "Da palavra encantatória à palavra desencantada, e desta à palavra

Ты - душная, как май, Яамская, / Шевардина ночной редут / ГАе тучи стоны испускают / И врозь по роспуске илут.

И в рельсовом витье Авояся, - / Предместье, а не перепев, - / Ползут с вокзалов восвояси / Не с песней, а оторопев.

Отростки Аивня грязнут в гроздьях / И долго, Аолго до зари / Кропают с кровель свой акростих, / Пуская в рифму пузыри.

Поэзия, когда под краном / Пустой, как цинк ведра, трюизм / То и тогда струя сохранна, / Тетрадь подставлена - струись! (ПАСТЕРНАК, 1961, р. 101) 
errante da escritura" (CAMPOS, 1979, p. 143). Nesse complexo percurso do poeta brasileiro, a experiência tradutória dos textos meta-poéticos de Pasternak parece corresponder à segunda etapa, a do desencantamento e do "contra-movimento do poema" (CAMPOS, 1979, p. 143), sem que surja ainda a afirmação da ironia.

Se aos olhos de Jakobson a linguagem poética de Pasternak é o domínio no qual as metonímias se afirmam em sua especificidade, confirmando, com isso, a intensidade de seus efeitos, é porque as preocupações formais relativas à sonoridade, exacerbadas no sentido da deformação no âmbito da poesia transmental dos outros futuristas, adquirem aqui um desdobramento autorreflexivo por meio da encenação da voz do poeta. A voz encenada metonimicamente no poema parece corresponder, assim, a um efeito de duplicação, ao desnudamento dos procedimentos formais do texto, à "autorrepresentação, que diz respeito à própria construção e andamento da obra", que contém ainda "uma lembrança, uma correspondência com o dividir-se do sujeito" (ROSOLATO, 1976, p. 214). Não-canto, a voz rouca do poema de Pasternak afeta também a recepção do texto, revelando-se sugestiva dos aspectos rítmicos da leitura performática do texto.

Mas a duplicação, inerente à problemática dos processos da representação, não se limita à autorreflexividade, envolvendo também os limites ideológicos do dizer e as materialidades relacionadas com a articulação da palavra humana. Além disso, transformada no receptáculo dos fenômenos calados, "a voz incorpora em seu fluir tudo o que não é dito, como uma espécie de coleta de tudo o que foi sacrificado" (ROSOLATO, 1976, p. 220). Destarte, a voz enrouquecida faz pensar não apenas na intensidade do esforço do corpo, mas também nos efeitos das transmissões artificiais que provocam a impressão de sua impureza, tal um alto-falante.

Ao levantar a questão da dicção lírica e de sua reelaboração no âmbito da vanguarda futurista, o próprio Pasternak comentou-a da seguinte maneira: "o poeta não é o autor, mas o objeto da lírica que se dirige ao mundo em primeira pessoa" (PASTERNAK, 1959, p. 136). Destarte, o poeta russo coloca em questão a autoridade com relação à produção do 
sentido, insistindo na relevância dos elementos rítmicos do poema, dos quais participa também a voz. Em sua crítica antropológica do ritmo, Henri Meschonnic ressalta as qualidades eminentemente rítmicas da voz, insistindo também na complexidade da relação entre a oralidade e a espacialidade:

O sujeito e a história dissolvidos na estrutura, a estrutura foi linguagem sem voz. A voz não se acrescenta à estrutura. Oralidade e espacialidade, em suas diversas relações segundo as culturas, são inseparáveis. A oralidade exigiria uma antropologia comparada da dicção, dos modos de oralidade, tanto quanto das técnicas do corpo. E também buscar saber o porquê da antiga metáfora, estereótipo ainda em uso, característico do discurso tradicional sobre a literatura, que faz dizer: a voz de um escritor. (MESCHONNIC, 1982, p. 276)

A encenação da oralidade, assim como a inscrição da voz do poeta no fluxo rítmico do poema não se transforma na predominação da função expressiva, ainda que coloque em questão os limites da função poética pelo fato de questionar a sintomatologia da voz considerada em sua proximidade com o corpo:

Apenas tomando aquilo que registra, em desordem, um dicionário analógico do francês, a voz possui aquelas mesmas características que são atribuídas ao ritmo: altura, intensidade, timbre, entonação e, aquelas que a distinguem, inflexão e sotaque (no sentido de entonação regional). A voz tem suas características próprias, físicas, fisiológicas (a idade): ela é feminina ou masculina, jovem, madura, senil, encorpada ou branca, quente ou áspera. Existe também uma sintomatologia pela voz: ela é vigorosa ou sofrida, trêmula, quebrada, fresca, rouca, melosa, vínica. Por fim, tem a enunciação, o enunciador, na voz, carregada ora de suas emoções, ora de seu trato dos outros, trato quer dito subjetivamente, quer enunciado tal como é recebido pelo outro: voz encantadora, comovida, carinhosa, queixosa, seca, irónica cortante, dilacerante, suplicante, polida ou grosseira. A voz é seminal: há emissão de voz... (MESCHONNIC, 1982, p. 292)

Além de ser marcada pelo sintoma e, dessa forma, afirmando-se em seus aspectos de uma técnica do corpo, convencional e inscrita no âmbito de uma tradição cultural, a voz enrouquecida encenada no poema de Pasternak, parece ganhar sua força simbólica em algum nível inferior de expressão, sugerindo uma perturbadora semelhança com os desvios 
da enunciação pública de um discurso político. Meschonnic insiste em seu estudo na dimensão demagógica e na iminência do desnudamento do registro patológico inerentes a uma técnica do corpo por demais singularizada:

\begin{abstract}
Voz de tórax, voz de cabeça, de garganta, de nariz. As variações modificam não apenas as vogais, elas condicionam a proferição da pessoa. Os oradores políticos fazem disso mais um médium do que um meio. Tem uma irradiação da voz. Lucrécio teria compreendido isso materialmente, como para o sol, ele, que atribuía à voz uma natureza molecular (De rerum natura, IV, v. 524-547). Tudo aquilo que desorganiza o ser humano, que o dissocia, desestrutura a voz, faz a linguagem regredir à glossolalia como em Artaud. Tudo que leva a voz de volta à natureza, leva-a, à contra-linguagem, ao grito. A escuta moderna do Oriente, de seu teatro, de sua música, contribuiu para a descoberta da antropologia da voz. Essa exploração já estava em "Sprechgesang", no Pierrot lunaire de Schönberg em 1912. Os expressionismos da voz irracionalizam-na. Quando a voz se mescla ao silêncio, ela se aproxima do grito. Contra a linearidade da linguagem, a voz é um plural interno, uma simultaneidade. A voz é sinoral, como se diz sinótico. (MESCHONNIC, 1982, p. 292)
\end{abstract}

Ao descrever o trabalho com a voz na arte do ator do teatro pós-traumático, Jerzy Grotowski insiste na inscrição das capacidades vocais do ser humano no corpo e na história do sujeito:

Tudo aquilo que remete às associações dirigindo-se ao espaço libera a voz. Libera - sobretudo nos estudos musicais - não os impulsos frios, mas as investigações no campo de nossas próprias lembranças, de nosso corpo-memória. Isso cria a voz. Existe então apenas um único problema: como liberar aqueles impulsos do corpo-memória? Ou até mesmo: do corpo-vida? Não é possível o trabalho com a voz sem o trabalho com o corpo-vida. (GROTOWSKI, 2012, p. 415)

Articulada por meio de uma respiração ruidosa, a voz doente do poema "Poesia" assinala em 1922 a extrema dificuldade da relação entre a linguagem poética, a articulação do espaço lírico e a inscrição da obra de arte no contexto da violência política e histórica. Afetada tanto fisiológica quanto moralmente, a voz do poema pasternakiano é entregue aos excessos rítmicos, atravessando o caminho do grito injurioso até a situação de quase sufoco. "O caráter autodestruidor dos enunciados figurativos proíbe ao problema de sua decodificação 
qualquer solução linguística", um dos efeitos da linguagem figurativa sendo o "de distanciar-nos do código" (GRUPO MU, 1997, p. 15). A insistência nos efeitos da metonímia no poema de Pasternak exacerba a impressão da violência, fazendo com que esta ultrapasse a provocação auto-reflexiva da proliferação do sentido referencial, passando a questionar, por meio da tematização da voz "do poeta", a situação ideológica do discurso poético, estranhamente próxima também da situação da expressão verbal de um conflito, senão da tentativa de uma maldição.

Conhecido já nos anos 20 pela “extraordinária agudeza analítica de sua visão” (apud. PASTERNAK, 1959, p. 13), o poeta russo participou de um movimento futurista menor, observando criticamente seu desenvolvimento maior, sobretudo na potente e imponente figura de Vladimir Maiakovski. A perturbadora simultaneidade da poesia da vanguarda com a confirmação da eficácia prática dos discursos ideológicos e propagandísticos no tempo da revolução e da guerra confirmou, de fato, a situação da ruptura da fronteira entre arte e vida, fazendo com que a linguagem poética passasse a ocupar um lugar dúbio, por demais próximo dos discursos da política e da religião. "Na voz, o mais fisiológico já é social. Como o indivíduo. A voz é assim situada diferentemente não apenas segundo as culturas, mas também segundo as antropologias. A voz está associada à magia pelo encantamento, antes do canto" (MESCHONNIC, 1982, p. 293), advertia Meschonnic. A estranha eficácia da palavra poética aproxima-se da palavra ideologicamente comprometida praticada no âmbito dos ritos e dos rituais e, nesse sentido, o poema "Poesia" leva à formulação de uma crítica de certas acepções do engajamento da literatura e da arte.

\section{"MA VOIX DEVIENT RAUQUE": LA MÉTONIMIE DANS LA POÉSIE DE BORIS PASTERNAK}

RÉSUMÉ: La coïncidence de l'invention de la diction futuriste, à laquelle participe très activement la poésie de Boris Pasternak, avec la confirmation de l'efficacité pratique des discours idéologiques et de la publicité à l'époque de la révolution et de la guerre, a causé la violation de la frontière entre l'art et la vie. Le domaine du langage poétique devient incertain, proche des interventions de la politique et de la religion. La mise en scène de la voix marquée par le symptôme et décrite dans ses aspects d'une technique du corps, conventionnelle et située dans le cadre d'une tradition culturelle, est vigoureuse dans son poème futuriste « Poésie », traduite au Brésil par Haroldo de Campos. En répresentant 
une voix qui gagne son efficacité dans un niveau inférieur d'expression, le texte suggère une ressemblance troublante avec les déviations de l'énonciation d'un discours publique d'un politicien. Dans sa critique anthropologique du rythme Henri Meschonnic insiste sur la dimension sintomatologique de la pratique pathologique inhérente à une technique du corps trop singularisée. Chez Pasternak, l'efficacité de la parole poétique articulée par la métonymie met le mot idéologiquement compromis utilisé dans le cadre des rites et des rituels en contact avec le langage poétique, ouvrant le chemain vers la formulation, dans la « Poésie », d'une critique de certaines dimensions de l'engagement de la littérature et de l'art.

MOTS-CLÉ: avant-garde; language poétique; métonymie; violence; voix

\section{REFERÊNCIAS:}

AL-SHARAFI, M. G. Abdul. Textual Metonymy. A Semiotic Approach. Nova Iorque: Palgrave Macmillan, 2004.

AUCOUTURIER, Michel. "Prose et poésie chez Pasternak". In. Révue des études slaves, 67, 1995, pp. 589-596.

CAMPOS, Haroldo de. Signância quase céu. São Paulo: Perspectiva, 1979.

CAMPOS, Augusto de et al. Poesia Russa Moderna. São Paulo: Perspectiva, 2001.

DENIS, Lily. Rilke, Pasternak, Tsvétä̈va. Correspondência a três. Trad. A. Silva Carvalho. Lisboa: Assírio\&Alvim, 2006.

GROTOWSKI, Jerzy. Teksty zebrane. Varsóvia: Instytut Teatralny, 2012.

GRZYWACZ, Malgorzata. "Rilkesche Reminiszenzen bei Marina Zwetajeva. Über einige Aspekte der Ikone im Werk der russischen Muse”. In. FURTADO, Maria Teresa et al. (org.). Rilke 70 anos depois. Colóquio interdisciplinar. Lisboa: Colibri, 1996, pp. 215-222.

GRUPO MU. "Miroirs rhétoriques: sept ans de réflexion”. In. Poétique 29. Paris: Seuil, 1997, pp. 1-19.

HEISTEIN, Josef. “Le futurisme dans les littératures européennes”. In. Europe 551, 1975, pp. 12-29.

JAKOBSON, Roman. "Marginal Notes on the Prose of the Poet Pasternak". In. DAVIE, Donald e LIVINGSTONE, Angela. Pasternak. Londres: Macmillan, 1969, pp. 135151.

. My Futurist Years. Trad. S. Rudy. Nova Iorque: Marsilio Publishers, 1992.

. Linguistica e Comunicação. Trad. I. Blikstein e J. P. Paes. São Paulo: Cultrix, 1995.

. “O futurismo”. Trad. S. R. M. Gonçalves. In. RUS 12, 2018, pp. 146-154.

LANNE, Jean-Claude. "Pasternak et le futurisme russe". In Europe, 1993, pp. 48-57. 
MESCHONNIC, Henri. Critique du rythme. Anthropologie historique du langage. Paris: Verdier, 1982.

PASTERNAK, Boris. Salvoconducto. Trad. H. Zernask. Buenos Aires : Editorial Dedalo, 1959.

1959.

. Gedichte. Erzählungen. Sicheres Geleit. Trad. A. Kaempfe et al. Frankfurt: Fischer,

ПАСТЕРНАК, Борис. Стихи и поэмы 1912-1932. Nova Iorque: The University of Michigan Press, 1961.

ROSOLATO, Guy. "A voz e o mito literário”. In. A controvérsia estruturalista. As linguagens da Crítica e as Ciências do Homem. Trad. C. A. Vogt e C. Sabóia Madureira. São Paulo: Cultirx, 1976, pp. 213-229.

STALER PASTERNAK, Lydia. Pasternak Fifty Poems. Londres: Unwin Books, 1972.

TSVETÁIEVA, Marina. Indícios flutuantes. Trad. A. F. Bernardini. São Paulo: Martins Fontes, 2006.

Recebido em: 31/07/2019.

Aprovado em: 22/05/2019. 